\title{
EL GRACIOSO TRÁGICO CALDERONIANO: UN CASO DE MULTIPLICIDAD ${ }^{1}$
}

\author{
Juan Manuel Escudero \\ Departamento de Literatura Hispánica \\ Edificio de Bibliotecas \\ GRISO-Universidad de Navarra \\ 31080 Pamplona. Navarra. España \\ jescudero@unav.es
}

[Anuario calderoniano (ISSN: 1888-8046), 3, 2010, pp. 115-135]

Las tragedias calderonianas muestran en casi todos los casos la inserción de un personaje gracioso que suele ser el hilo conductor de la risa. Mucho se ha escrito sobre este asunto a lo largo de los últimos años, aunque aun se echa de ver la falta de un estudio de conjunto sobre el gracioso calderoniano. Ni siquiera existe hoy día un estudio parcial sobre el gracioso en el subgénero trágico. El germen de un futuro trabajo sobre este campo tendría que partir necesariamente de las etiquetas genéricas que en su día Lope estableció en su Arte Nuevo, donde admitía la existencia de un término híbrido como la tragicomedia que, resultado de la mezcla de elementos trágicos con cómicos, debería ser el terreno natural donde ubicar al gracioso trágico. Sin embargo, como señala Arellano ${ }^{2}$ en un agudo análisis sobre este aspecto:

1 Este trabajo cuenta con el patrocinio de TC-12 en el marco del Programa Consolider-Ingenio 2010, CSD2009-00033, del Plan Nacional de Investigación Científica, Desarrollo e Innovación Tecnológica.

2 Ver Arellano, "Lo trágico y lo cómico mezclado: de mezclas y mixturas en el teatro del Siglo de Oro", en prensa. La idea de este trabajo surgió al aplicar su base teórica con algunas tragedias de Calderón. Lo que sigue en estos primeros párrafos 
En cualquier caso se advierte una notable tendencia a ponderar la mezcla o mixtura trágica, pero sin argumentos ni precisiones mayores, y sin (de)mostrar en qué consiste exactamente dándole por evidente e inmediatamente percibible sin más indagación, o haciendo distinciones poco elaboradas.

Es decir, se da por sentada la existencia de la mezcla pero falta un desarrollo razonado de las posibilidades combinatorias, de la cantidad concreta del ingrediente trágico y cómico, o de su rango principal o secundario, pues su mezcla no afecta al nivel categórico. De manera que una tragedia con elementos cómicos, sigue siendo una tragedia, con un efecto determinado sobre el público receptor, y donde necesariamente lo cómico se subordina a lo trágico. En este caso, más que la mezcla lo que se debería constatar es cómo el dramaturgo inserta ese mundo risible en el marco general de la tragedia o de lo serio. De una manera inversa, en un marco global donde predomina el elemento cómico, traza principal, el uso de situaciones trágicas no anula el efecto cómico dominante; se produce lo que Vitse ${ }^{3}$ llama con acierto «una especie de anestesia afectiva, un distanciamiento», que vacía de contenido trágico a tales situaciones. Aquí juega un papel decisivo la pericia, el oficio del dramaturgo a la hora de disponer estos elementos secundarios sobre los principales. Arellano, de nuevo, señala con meridiana precisión dos posibilidades: 1. Mezcla simple de elementos cómicos, generalmente por responder a las expectativas del público; 2. Otros tipos de inserciones más complejas.

Ambas posibilidades no tienen nada que ver con un progresivo perfeccionamiento de la fórmula lopiana, que va desde la mezcla simple a una integración en varios niveles. Se trata más bien, de un problema de capacidades artísticas. Hay dramaturgos con mayor habilidad de manejo de ambos planos; los hay incapaces; y los hay quienes alternan obras donde se observa una variopinta búsqueda de fómulas combinatorias que van desde la inserción simple a esquemas de mucha mayor complejidad, dependiendo del caso. Calderón es, a mi modo de ver, un ejemplo muy interesante de búsqueda de una integración verosímil de ambos planos (con la convicción del predomio del efec-

es una muy sucinta exposición de su trabajo, que considero esencial para explicar los conceptos de mezcla simple e inserción compleja.

${ }^{3}$ Ver Vitse, 1998, p. 37. 
to trágico sobre el cómico). Sus obras trágicas (las cómicas plantean otros problemas) apuntan hacia la armonía de ambos planos.Y no hay desde luego una evolución cronológica, sino una asistemática constelación de soluciones que demuestran, una vez más, sus dotes de excelente dramaturgo. De manera provisional se pueden sugerir los siguientes caminos:

1. Un tipo de inserción simple. Arellano señala con acierto el ejemplo de Persio en La gran Cenobia o de Polidoro en la versión impresa de El mayor monstruo del mundo, en cuya versión manuscrita conservada, una reescritura posterior, sintomáticamente Calderón reduce el número de sus intervenciones ${ }^{4}$.

2. Varios ensayos de inserción más compleja que abarcan un amplio abanico de posibilidades que van desde la plurifuncionalidad, como es el caso de La hija del aire (primera y segunda parte), estudiada hace no mucho por Rubiera ${ }^{5}$; la búsqueda de nuevos graciosos como la figura del bufón, cuya locura es ambivalente, pues permite a un mismo tiempo expresar y anular la verdad: el Pasquín de La cisma de Ingalaterra, o la disolución total del gracioso en el ambiente trágico que conlleva su anulación como figura del donaire como ocurre con Coquín en El médico de su honra.

3. Casos mixtos, donde se observa una mezcla de inserciones simples y complejas en más de un personaje con función lúdica, como si se pudiera hablar de una especie de generalización del agente cómico (como parece ocurrir en las comedias de capa y espada). Un buen ejemplo de esto último me parece que es El alcalde de Zalamea. A esta obra voy a dedicar las siguientes páginas.

${ }^{4}$ Como se sabe, la impresa, más temprana, aparece en la Segunda parte de comedias, bajo el cuidado de José Calderón impresa en Madrid por María de Quiñones en 1637. La versión manuscrita, parcialmente autógrafa, lleva fecha de 1667, y es mucho más extensa que la primera, aunque elimina escenas enteras donde interviene el gracioso Polidoro, justamente porque Calderón ve inoperativas desde el punto de vista dramático esas inserciones. Ver más detalles en Ruano, 1998, o Caamaño Rojo, 2002. Arellano también señala con acierto las diferencias entre ambas versiones (2006a, pp. 38-41).

${ }^{5}$ Ver Rubiera, 2005. 
Es curioso que una obra como El alcalde de Zalamea, considerada una de las obras maestras del teatro calderoniano, no haya recibido por parte de la crítica una mayor atención en relación a la figura del gracioso. Probablemente porque, de manera inconsciente, la obra presenta algunas peculiaridades en relación con este punto que merecen ser discutidas. En efecto, en El alcalde, varias son las parejas de personajes que tienen su propia función cómica: Rebolledo y La Chispa; Don Mendo y Nuño; y finalmente el propio Pedro Crespo y Don Lope de Figueroa. Vayamos por orden.

\section{Rebolledo y La Chispa.}

Ambos personajes señalan desde el inicio de la comedia un marcado parentesco con otro modelo de personaje marginal: el pícaro. Sin duda, el germen de esta unión hay que buscarlo en el Guzmán donde Alemán explora las estrechas relaciones entre el personaje picaresco y la vida militar de la soldadesca ${ }^{6}$. Y si tan fecunda unión nace ya con el Guzmán, esta línea híbrida recorre todo el espectro picaresco hasta llegar al final del ciclo con el Estebanillo González, publicada en 1646, novela que parece mantener una estrecha relación textual con El alcade de Zalamea. El diseño, por tanto, del personaje gracioso bajo esta perspectiva cobra especial relieve. Rebolledo se alza, así, como arquetipo del mal soldado, La Chispa como ejemplo de soldadera que acompaña al ejército. El primero aparece caracterizado como jurador empedernido (con un «iCuerpo de Cristo!» arranca la comedia); se queja de su suerte errante, asimilándose a los gitanos (v. 5); juega con chistes dilógicos que aluden a su penuria económica (la comparación jocosa entre las órdenes monacales y mendicantes de los vv. 30 y ss.), y en su primera aparición su único deseo llegado el caso es el de dar un tornillazo (que parece no ser el primero, vv. 42-43). En el transcurso de la primera jornada muestra su inveterada afición al juego (recuérdese toda la escena referida al juego del boliche que solicita como ayuda de costa para paliar su maltrecho patrimonio). Otros detalles

${ }^{6}$ Recuérdese que los puntos de contacto entre el pícaro como personaje y las autobiografias de soldados del siglo XVII son constantes. Ver Miguel de Castro, Vida del soldado Miguel de Castro, 1956; Jerónimo de Pasamonte, Vidas y trabajos de Jerónimo de Pasamonte, 1956; Alonso de Contreras, Discurso de mi vida, ed. Ettinghausen, 1988; Diego Duque de Estrada, Comentarios del desengañado de sí mismo, ed. Ettinghausen, Madrid, Castalia, 1982. Ver más datos en Cassol, 2000 b. 
menores ${ }^{7}$ aluden a sus continuas ganas de pendencia, o su cobardía a la hora de encubrir a su superior ante la amenza de recibir tratos de cuerda $^{8}$. Para La Chispa, el dramaturgo se sirve de otros modelos algo alejados de los estrictamente picarescos. Desde su entrada en escena su registro lingüístico, y el de Rebolledo9; la señalan como una recreación del hampa germanesca con marcas léxicas distintivas como «Seor» (v. 65), "postema» (v. 84), a las que hay que añadir chistes de carácter escatológico y sexual como los juegos de palabras con regla ${ }^{10}$ (vv. 74-80) o la propia onomástica del personaje:

7 Otros síntomas de su negativa caracterización parecen recorrer el texto; recuérdese la arrollada bandera que puede ser dato a tener en cuenta.

${ }^{8}$ Recuérdese que en esta escena parte de la comicidad tiene una elaboración formal a partir de los juegos dilógicos con la palabra tratos (Don Lope.- Denle dos tratos de cuerda. / Rebolledo.- ¿Tras... qué me han de dar, señor? / Don Lope.- Tratos de cuerda. Rebolledo.- Yo hombre / de aquesos tratos no so soy, vv. 815-818; todas las citas proceden de la edición de Escudero, 1998).

${ }^{9}$ Rebolledo se refiere a ella como "pobreta»; v. 63; «la persona», v. 64, iniciando, así, un proceso de germanización. Recuérdese que cuando va a recibir tormento, la propia Chispa le invita jocasamente a que no cante: «Rebolledo, determina / negarlo punto por punto; / serás, si niegas, asunto / para una jacarandina / que cantaré» (vv. 2394-2398). En varios textos literarios del Siglo de Oro se hace referencia, dentro del mundo germanesco, a esta actitud considerada como positiva de no cantar (confesar) durante la aplicación del tormento. Comp. C. de Chaves, Relación de la Cárcel de Sevilla, p. 16: «Y si le dan tormento y niega, le reciben con sábanas rociadas de vino, y con vigüelas y con panderetes. Por el contrario, si confiesa, no le admiten en su alojamiento que llaman rancho, y trátanlo de manera, que se viene a acomodar con la peor gente de la prisión»; Quijote, I, cap. 22: «va siempre pensativo y triste, porque los demás ladrones que allá quedan y aquí van le maltratan y aniquilan, y escarnecen, y tienen en poco, porque confesó y no tuvo ánimo de decir nones».

10 Otro chiste de carácter erótico se recoge en los versos 2408-2409 con el juego de palabras entre brida y jineta como dos formas diferentes de cabalgar: a la jineta o «recogidas las piernas en el estribo» (Diccionario de Autoridades); o a la brida o "con los estribos largos, al contrario de jineta" (Diccionario de Autoridades). Con esta contestación grosera, alude chistosamente la Chispa al acto sexual; no hay que olvidar su profesión de soldadera y prostituta de la milicia. Comp., entre los muchos posibles, algunos ejemplos en Quevedo, Tasa de la herramienta del gusto, Prosa festiva completa, p. 304: «mandamos [a la mujer flaca] que en ningún tiempo se puedan ensillar, si no es con silla de borrenes, como postas y caballos saltadores, que no hagan mataduras y lastimen con sus huesos por lo mucho que se menean"; id., Poesía original, núm. 776, vv. 25-26: «Las putas y los caballos / son los que más se cabalgan». Ver más ejemplos en Poesía erótica del Siglo de Oro, núm. 99, vv. 53-56; o núm. 108, vv. 9-11: 
[...] no dejara

en mi vida, cosa es clara,

la casa del regidor,

donde todo sobra, pues

al mes mil regalos vienen;

que hay regidores que tienen

menos regla con el mes.

La caracterización del personaje se cierra en esta primera intervención con la primera jácara que canta acompañada del propio Rebolledo (vv. 101-112)11:

\begin{tabular}{|c|c|}
\hline Chispa & $\begin{array}{l}\text { Yo soy tiri, tiri, taina } \\
\text { flor de la jacarandaina. }\end{array}$ \\
\hline REBOLLEDO & $\begin{array}{l}\text { Yo soy tiri, tiri, tina, } \\
\text { flor de la jacarandina. }\end{array}$ \\
\hline Chispa & $\begin{array}{l}\text { Vaya a la guerra el alférez, } \\
\text { y embárquese el capitán. }\end{array}$ \\
\hline REBOLLEDO & $\begin{array}{l}\text { Mate moros quien quisiere, } \\
\text { que a mí no me han hecho mal. }\end{array}$ \\
\hline Chispa & $\begin{array}{l}\text { Vaya; y venga la tabla al horno, } \\
\text { y a mí no me falte pan. }\end{array}$ \\
\hline REBOLLEDO & $\begin{array}{l}\text { Huéspeda, máteme una gallina; } \\
\text { que el carnero me hace mal. }\end{array}$ \\
\hline
\end{tabular}

«El tuétano sabroso está en los huesos, / y, con traer cojín quien me cabalga, / sin mataduras correrá a la brida». Por otro lado, son usuales en el Siglo de Oro, los juegos de palabras con ambos conceptos (brida y jineta), acompañados a veces de las mismas connotaciones eróticas; comp. Lope de Vega, El mesón de la corte, en Tres comedias madrileñas, p. 93: «Dame a la bella Juanilla, / si no en pelo, con la silla: / sea a la brida o jineta, / que en altar de su seta / ofreceré mi tablilla»; Quevedo, Premática contra las cotorreras, Prosa festiva completa, p. 335: «Asimismo, mandamos que cuando las dichas hermanas os dejáredes ensillar, sea de brida o jineta, no deis lengua si no os la piden, so pena que os la morderán».

${ }^{11}$ Para mayores precisiones sobre fuentes y textos paralelos de esta jácara, remito a mi edición de El alcalde donde el lector encontrará abundante información. Parte de la misma aparece recogida en el Estebanillo. Relación no casual que refuerza la idea de un gracioso construido a partir de notas picarescas. 
A la que hay que añadir la que aparece registrada en los versos 1321-1338

\begin{tabular}{|c|c|}
\hline CHISPA & $\begin{array}{l}\text { Érase cierto Sampayo, } \\
\text { la flor de los andaluces, } \\
\text { el jaque de mayor porte } \\
\text { y el jaque de mayor lustre. } \\
\text { Éste, pues, a la Chillona } \\
\text { topó un día... }\end{array}$ \\
\hline Rebolledo & $\begin{array}{l}\text { No le culpen } \\
\text { la fecha; que el consonante } \\
\text { quiere que haya sido en lunes. }\end{array}$ \\
\hline ChIspa & $\begin{array}{l}\text { Topó, digo, a la Chillona, } \\
\text { que, brindando entre dos luces, } \\
\text { ocupaba con el Garlo } \\
\text { la casa de los azumbres. } \\
\text { El Garlo, que siempre fue, } \\
\text { en todo lo que le cumple, } \\
\text { rayo de tejado abajo, } \\
\text { porque era rayo sin nube, } \\
\text { sacó la espada, y a un tiempo } \\
\text { un tajo y revés sacude... }\end{array}$ \\
\hline
\end{tabular}

Una vez fijadas las marcas cómicas de ambos peronajes, Calderón toma la decisión de convertirlos en agentes activos del armazón trágico. En efecto, cuando la estructura tracista comienza a desarrollarse plenamente a partir de la mitad de la primera jornada, Rebolledo y La Chispa van a participar de manera activa en el encadenamiento de los acontecimientos, y su aparición en la simétrica estructura de la obra no deja de ser un acierto del propio dramaturgo ${ }^{13}$. Ambos personajes van a intervenir de forma decisiva en la preparación de los tres

12 El tono de esta última es más literario, en cuanto imitación deliberada de los modelos quevedianos. Remito de nuevo a mi edición de El alcalde donde anoto los distintos intertextos que utiliza Calderón.

13 Parker («La estructura dramática de El alcalde de Zalamea», 1991a, p. 73) señaló en su momento una acertada estructura de triángulos invertidos. Para otros estudios sobre la rígida disposición estructural de la comedia, ver Halkhoree, 1971 y 1972; Leavitt, 1966; Sabor de Cortázar, 1982; Sloman, 1951;Vitse, 1988, pp. 277-283. Para más detalles remito a mi edición de El alcalde, 1998, pp. 22-37. 
asaltos que intenta el capitán para raptar a Isabel. De hecho, son sus catalizadores, y su presencia en la segunda y tercera jornada hay que ponerla en relación con los momentos culminantes de la acción. Por la misma razón, su papel en la tercera jornada decrece; se limita éste a sus arrestos respectivos, aunque este último elemento es esencial porque Crespo para justificar su castigo/venganza contra el capitán necesita instruir un proceso ${ }^{14}$ y hacer pública la deshonra de su hija.

\section{Don Mendo y Nuño.}

Casi al comienzo de la primera jornada, cuando se produce el movimiento de penetración de las tropas desde el exterior hasta el interior del mismo pueblo de Zalamea, el Sargento comenta extrañado la visión de «un hombre, / que de un flaco rocinante / a la vuelta de esa esquina / se apeó, y en rostro y talle / parece aquel don Quijote, / de quien Miguel de Cervantes / escribió las aventuras» (vv. 214218). Más adelante se habla de don Mendo como «jinete de costa», v. 1296, o «alma en pena... con su adarga a cuestas», vv. 1315 y ss. Efectivamente el personaje tiene ver con la figura del hidalgo ${ }^{15}$ ("hidalgo de figura", como reza la acotación tras el verso 224) muy popular en el teatro entremesil del siglo XVII. Se trata de un homenaje que el propio Calderón hace a Cervantes y que repite en otras muchas comedias ${ }^{16}$. Aquí el personaje de manera jocosa hace constantes alusiones a su condición de hidalgo empobrecido y hambriento, realidad que es subrayada por su criado que, como un clarísimo alter ego de Sancho Panza opone la mirada idealista de su amo con su visión cómica y descarnada de la realidad. El contraste entre ambos mundos:

${ }^{14}$ Recuérdese que el texto lo señala de manera explícita: «Don Lope.- ¿Qué es proceso? / Crespo.- Unos pliegos de papel / que voy juntando, en razón / de hacer la averiguación / de la causa» (vv. 2597-2601).

${ }^{15}$ Ver Abrams, 1966.

16 Calderón debió de admirar a Miguel de Cervantes pues lo cita en varias ocasiones. Aquí hay un anacronismo: la acción se sitúa en 1580 y la primera parte de $E l$ Quijote se publicó en 1605. Alusiones a Cervantes y a su obra, aparecen en varias comedias de Calderón (contabilizadas alrededor de 20 alusiones): Dicha y desdicha del nombre, Mañana será otro día, La dama duende, Manos blancas no ofenden, El sitio de Bredá, etc. Ver Wilson, 1982; Robert Ter Horst, 1982; Sánchez, 1957, espec. pp. 266-267. Y más recientemente, Arellano, 2006b, espec. pp. 138-142. 
el ideal, en este caso, deformado hacia lo grotesco, y el de la grosera materialidad crean situación hilarantes (vv. 225-234):

Mendo ¿Cómo va el rucio?

NuÑO

$$
\text { Rodado, }
$$

pues no puede menearse.

MENDO ¿Dijiste al lacayo, di, que un rato le pasease?

NUÑO

MENDO ¡Qué lindo pienso!

NUÑO

No hay cosa que tanto a un bruto descanse.

MeNDO Aténgome a la cebada. ¿Y que a los galgos no aten dijiste?

NuÑo

Ellos se holgarán; mas no el carnicero.

La fisonomía ridícula del hidalgo se completa con otras alusiones referentes a la saliva como quitamanchas (greda, en el texto, v. 305), o la impostura del protagonista de calzarse pallillo y guantes para simular una opípara comida (vv. 235 y ss.). Rasgo este que junto a los chistes posteriores referentes a la mesa divina «sin medios, postres ni antes» señalan también un cruce de la réplica cervantina con la figura del escudero del Lazarillo $^{17}$, con hipotéticas implicaciones como señalaré más tarde. Otras tachas morales acompañan a las de su fisionomía, como un apego enfermizo a una ejecutoria que le dejó su padre, fisicamente visible, vv. 259-264:

En buen descanso esté el alma de mi buen señor y padre, pues, en fin, me dejó una ejecutoria tan grande, pintada de oro y azul, exempción de mi linaje.

17 Arellano no duda de esta duplicidad de modelos (2006b, p. 139). 
o su desprecio por las mujeres, dado que corteja a Isabel pero no para casarse con ella, por su condición villana, sino para encerrarla en un convento (¿Pues no hay, sin que yo me case, / Huelgas en Burgos, adonde / llevarla, cuando me enfade?); o el maltrato ridículo a su criado con una estética propia del género entremesil (vv. 920 y ss.); o la cobardía por miedo al enfrentamiento con el capitán, que le lleva a entrometerse en su ardid por conseguir a Isabel pero incapaz de llevar a cabo otra acción trascendente fuera de la de sentarse y esperar. Y sentado acabará recibiendo palos de nuevo como un personaje de entremés.

En total, cuatro son las intervenciones de este personaje y de su criado a lo largo de la comedia, una en la primera jornada y tres en la segunda. Calderón se olvida por completo de su existencia en la tercera jornada. Su presencia, pues, es anecdótica y obedece más a una especie de homenaje literario por parte del dramaturgo que a una intencionalidad de un desarrollo más complejo. No obstante, el que ambos personajes no se signifiquen de manera importante en la arquitectura dramática no quita para que en Calderón, su posición y desarrollo dentro del drama obedezca a pensadas decisiones de construcción ${ }^{18}$. Don Mendo vendría a ocupar esa parcela del fresco social de Zalamea de los indignos con honra, frente a los dignos sin honra, villanos como Pedro Crespo, respaldado por su riqueza agraria de la

18 No hay unanimidad en la crítica acerca de la operatividad de ambos personajes. Wilson, 1982, p. 11, ve poca integración en la trama central. Por el contrario, Abrams, 1966, p. 27, señala «una marcada influencia del Quijote a través de los tres actos», visión exagerada como muy bien demuestra Arellano, 2006b, pp. 139 y ss., quien señala con acierto (pp. 141-142): «La superficialidad de la imitación quijotesca no debe hacer pensar, sin embargo, que el personaje de don Mendo es en sí mismo irrelevante en la obra. Las cosas son algo más complicadas, pues don Mendo, con su orgullo de hidalgo hambrón, su desprecio por los villanos, su negativa a pensar en casarse con Isabel, refleja en tono bufo la misma actitud que muestra el capitán, funcionando como ilustración secundaria del conflicto trágico central. En otra vertiente, el hidalgüelo no establece oposición solamente, como se suele estimar por la crítica, con Pedro Crespo, sino también con los soldados y los nobles militares (se declara capaz de echarlos a todos a cuchilladas, pero pasa al lado disimulando, por cobardía: vv. 1305 y ss., 1423-1424), creando así, dentro de los límites de Zalamea, un verdadero microcosmos social y estamental, en el que los villanos han de soportar las demasías de diversas especies de nobles degenerados, a los que se oponen también los buenos militares como don Lope de Figueroa». 
que carece por completo el pobre hidalgo. En el fondo, la acción que representa el hidalgo apareja en el imaginario colectivo la negación de su propia ejecutoria, ejecutoria que recuérdese podría haber comprado Crespo, y haber evitado de paso la tragedia sobre su familia. Pero aún hay más. Podría hasta aventurarse, cuanto menos, un plano connotativo no ajeno a ojos de un espectador o lector contemporáneo a la obra. Como he señalado antes flota alrededor de la recreación cervantina sutiles referencias al escudero del Lazarillo, a ese escudero, en suma, que dice ser oriundo de esa calle Costanilla de Valladolid $^{19}$, a ese escudero en suma más converso seguramente que otra cosa, lo que vendría a señalar que la figura calderoniana y su obsesiva defensa de sus privilegios pudiera esconder en el fondo la defensa de una impostura...

\section{Pedro Crespo y Don Lope de Figueroa.}

En rigor ninguno de estos dos personajes puede ser considerado figura de donaire en la comedia, pero en su confrontación (a diferencia de Crespo Don Lope nunca aparece separado de su interlocutor) trazan una serie de situaciones que lindan con los territorios de la risa. Estas situaciones de comicidad deben su origen tanto a la substancia constitutiva de ambos personajes como a su funcionalidad en el devenir de los sucesos. Su consciente combinación indica a las claras una inserción compleja de lo cómico en el entramado trágico, y que merece la pena analizar con más detalle.

Pedro Crespo ${ }^{20}$, protagonista indiscutible de la obra (es el personaje que permanece en escena casi toda la tercera jornada) muestra una complejidad sicológica que lo individualiza notablemente, y que tiene en cuenta, además, factores folclóricos que suponen pautas de comportamiento predeterminadas. Así, fuera de la toponimia que atestigua ya en el XVI el uso del nombre de «Crespo» en la región de Tole-

${ }^{19}$ Ver más detalles en el trabajo ya clásico de Rico, 1987, pp. 25 y ss., cita en pp. 31-32: «la simple mención de la Costanilla de Valladolid (común, sin duda, para referirse a jactancias fantasiosas, como en otro orden de cosas pudo serlo para motejar de cristiano nuevo) posiblemente bastara para inclinar a la suspicacia, para sugerir al lector de la época que el solar del escudero estaba situado en la región de las patrañas».

20 Para algunos datos sobre las caracterizaciones calderonianas del binomio padre-hijo, ver Vitse, 1988, pp. 283-294 y Parker, 1991 b. 
$\mathrm{do}^{21}$, éste aparece en varias comedias para designar a un alcalde (a veces un simple pastor), con caracterización cómica. Obras como el Romance pastoril de la elección del alcalde de Bamba, donde aparece un tal Antón de Herrán Crespo propuesto para alcalde; Pedro de Urdemalas de Cervantes, donde el nombre de Martín Crespo designa a un alcalde villano; Los novios de Hornachuelos (¿de Lope o Vélez de Guevara?); La Santa Juana (segunda parte) de Tirso, donde vuelve a aparecer un Crespo como alcalde aldeano; etc., dan testimonio de lo conocido del nombre. Incluso aparece en el primer capítulo del Guzmán de Alfarache $e^{22}$.

En casi todos estos ejemplos el nombre de Crespo designa a un personaje cómico de carácter resuelto, decidido y algo testarudo.

Dicha visión se potencia desde el principio de la comedia calderoniana por la intervención de otros personajes, anteriores a la salida de Crespo, que opinan desfavorablemente sobre su persona. Así, la primera mención se encuentra en boca del sargento:
En la casa de un villano que el hombre más rico es del lugar, de quien después he oído que es el más vano hombre del mundo, y que tiene más pompa y más presunción que un infante de León (vv. 165-171)

Si bien la perspectiva del sargento se revela poco fiable, sus palabras parecen recoger la opinión de los lugareños sobre su vecino Crespo. La segunda caracterización la hace Nuño quien resalta al parecer cierto deseo de Crespo de hacer hidalgos a sus nietos:

\author{
Pues con esto tú y su padre \\ remediaréis de una vez \\ entrambas necesidades: \\ tú comerás, y él hará \\ hidalgos sus nietos (vv. 320-324)
}

21 Para un rastreo del nombre «Crespo» en los siglos XVI y XVII, ver Salomon, 1985, pp. 128-129; Ynduráin, 1986, pp. 300-301.

${ }^{22}$ Ver la edición de Rico, 1987, p. 120 y n. 63. 
En suma, ambas alusiones a su persona, junto a las connotaciones folclóricas del nombre, presentan una visión desfavorable del protagonista antes de su entrada en escena. Después, el desarrollo trágico modulará de manera decisiva este comportamiento, y Crespo acabará adquiriendo toda una serie de rasgos positivos, empañados quizá por su exceso de prudencia que, a través de la ironía dramática, se va a convertir en el motor de la tragedia.

Por su parte, Don Lope resulta más complejo porque combina rasgos de personaje histórico y personaje dramático ${ }^{23}$. Don Lope de Figueroa y Barradas (éste era su nombre completo) nace en Guadix en el seno de una familia de la nobleza andaluza. Impresionante es su hoja de servicios: participó en las más célebres jornadas de los últimos años de Carlos V y de la época de Felipe II (los Gelves, Peñón de los Vélez, guerra de Flandes, batalla de Lepanto, guerra de Granada, jornada de las Islas Terceras); fue Maestre de Campo de Infantería Española, Maese de Campo General de Portugal, General de las Islas Terceras y de la Costa del Reino de Granada, Comendador de la Orden de Santiago de los Bastimentos del Campo de Montiel. Murió en Monzón el 1 de noviembre de $1585^{24}$. Pronto, el personaje histórico, convertido en mito para los ideales imperialistas, da en personaje dramático (como otro Diego García de Paredes) y aparece como protagonista de al menos ocho comedias: Lope de Vega, El asalto de Mastrique (1600-1606); autor desconocido (atribuido a Lope), El alcalde de Zalamea; Luis Vélez de Guevara, El águila del agua y batalla de Lepanto (1627?-1632?); Calderón de la Barca, Amar después de la muerte o el Tuzaní de la Alpujarra (1630?); Calderón de la Barca, El alcalde de Zalamea (1636); Luis Vélez de Guevara, El cerco del Peñón (impresa en 1634); Juan Bautista Diamante, El defensor del Peñón (impresa en 1670); Agustín Moreto, La traición vengada (impresa en 1681). Lo que

${ }^{23}$ Ver Hendriks, 1986. Lo mismo le ocurre a otro prototipo de militar legendario como Diego García de Paredes, también elaborado por Lope en comedias como La contienda de Diego García de Peredes, y el capitán Urbina; Las cuentas del Gran Capitán; y El blasón de los Chaves de Villalba. Ver Cassol, 2000a.

24 Esta sucinta reconstrucción biográfica, que corrige muchas inexactitudes de la tradición crítica, se debe a Arata, 2002, pp. 5 y ss., quien hace uso para la reconstrucción de la identidad histórica de Lope de Figueroa de la Historia del obispado de Guadix y Baeza de Suárez y el Libro del principio de la orden de caballería de Santiago de Mota. 
interesa, como demostró en su día Arata, es que tanto en las crónicas de la guerra de Flandes como en otras relaciones militares de la época se pone de relieve una serie de apectos morales del protagonista (positivos como la valentía, la lealtad) que nada tienen que ver con el rasgo físico de su cojera y su fama de renegador que lo definirán después como personaje dramático. Todo parece indicar que el responsable de esta primera elaboración, digamos, sui géneris fue Lope de Vega en El asalto a Mastrique ${ }^{25}$, donde se lleva a las tablas una de las hazañas más sonadas de la guerra de Flandes: el cerco y la posterior conquista de la ciudad de Maastricht (1579). Aparece en la obra lopiana un Don Lope minusválido, cuya pierna enferma es rasgo sintomático, jurador, jugador empedernido, con una sempiterna actitud de desafio feroz hacia la muerte, y una inclinación erótica que le lleva amancebarse con una mujer flamenca ${ }^{26}$. Es decir, se produce una desviación del modelo histórico hacia la creación de un personaje de dimensiones más populares, más cercano a lo que Nagy llama la picaresca castrense ${ }^{27}$. ¿Por qué se produce esta desviación en Lope? Contestar a esa pregunta no es desde luego el tema de estas páginas, pero puede esbozarse una hipótesis que contempla, de un lado, las peculiaridades genéricas de lo que Oleza ${ }^{28}$ llama dramas de hechos famosos, que en el primer Lope es un género bisagra que juega con la Historia y la ficción, y de otro, el hecho de que en esta comedia Don Lope ocupe una posición más cercana a la soldadesca que a los altos mandos militares, papel que desempeña en la comedia Alejandro Farnesio. ¿Esta peculiar visión del Don Lope histórico lopiano es compartida por el resto de obras que lo abordan como personaje? Tampoco es tema para ser tratado aquí. Sí me interesa, sin embargo, comentar cómo lo tra-

${ }^{25}$ Parece claro que la fuente directa que utilizó Lope para su comedia es la crónica histórica de Alonso de Vázquez, Los sucesos de Flandes y Francia en tiempos de Alejandro Farnese (que también fue fuente directa para otra crónica muy conocida en la época como Los españoles de Flandes. La obra de Vázquez ocupa los tomos 72-74 de la Colección de documentos inéditos para la Historia de España, 1879-1880. Manejo la edición del texto de Lope de E. di Pastena, Parte IV (vol. I) de Comedias de Lope de Vega, 2002. A su estudio me remito para mayores precisiones sobre las fuentes que utiliza Lope para su comedia.

${ }^{26}$ Otros muchos datos y contextos suficientes aporta Arata, 2002, pp. 7 y ss.

${ }^{27}$ Ver Nagy, 1981.

${ }^{28}$ Ver el estudio preliminar de Oleza a la edición de McGrady, Peribáñez y el comendador de Ocaña, 1997, pp. xlv y ss. 
tó Calderón en una obra anterior a su Alcalde como es Amar después de la muerte compuesta seguramente a principios de la década de los treinta, no mucho antes de que el propio dramaturgo escribiera El alcalde de Zalamea ${ }^{29}$. Una lectura atenta de ambas comedias en relación a la figura de Don Lope arroja manifiestas similitudes como la cojera física y un comportamiento dual que bascula entre el valor y la falta de paciencia. Todos los demás rasgos han sido eliminados en Calderón. Las razones de esta coincidencia de rasgos caracterizadores y de reducción del expectro morfológico hay que buscarlas en dos cuestiones que explican de manera clara el proceso dramático al que somete Calderón a su personaje. De manera global, como señala con acierto Arata $^{30}$, Amar después de la muerte (o El Tuzaní de la Alpujarra) es una clara anticipación de El alcalde de Zalamea:

El gran parecido entre dos obras pertenecientes a géneros tan distintos se explica por un dato que tiene especial importancia para la comprensión de la obra maestra de Calderón: El Tuzaní de la Alpujarra es un drama de cerco, como lo era El asalto de Mastrique de Lope. Sin embargo, como apuntó hace años Marc Vitse, también El alcalde de Zalamea tiene la estructura de un drama de cerco, por así decir «interiorizado», con el asalto militar, no a una ciudad cercada, sino a la casa de Pedro Crespo. Lo que hace Calderón en El alcalde de Zalamea es llevar a cabo una significativa contaminación: recupera los personajes y las situaciones de una comedia del honor campesino (el primer Alcalde), y los inserta en la estructura profunda de un drama de cerco, sobre el modelo de El asalto de Mastrique y de El Tuzaní de la Alpujarra, piezas que tenía muy presentes a la hora de componer su obra maestra. En este contexto, la figura anfibia de don Lope de Figueroa - personaje que procedía de un drama de cerco, pero que ya se había convertido en el protagonista de un drama campesino - iba a resultar decisiva.

${ }^{29}$ Manejo la reciente edición de Coenen, 2008, donde el editor, entre otras cuestiones señala con acierto la falsedad de la fecha de 1633 dada por Cotarelo como buena al confundir la obra calderoniana con la de Montalbán, Más puede amor que la muerte (ver su introducción, pp. 47 y ss.). Como señala el editor, la obra fue escrita al menos antes de 1659. Para la fecha de El alcalde, la de 1636 parece la más verosímil (ver Dixon, 2000).

${ }^{30}$ Ver Arata, 2002, pp. 11-12. 
Desde la perspectiva particular de la arquitectura teatral, tiene ver con el principio del decoro (y afecta de lleno a la concepción dramática de El alcalde). Acierta Arellano ${ }^{31}$ cuando comenta que «el protagonista real (léase alto), según las propias convenciones de la tragedia y las lealtades ideológicas vigentes, ha de mantenerse a un nivel de dignidad superior». Bances Candamo, aunque discípulo tardío de Calderón ${ }^{32}$, ilumina convenientemente este aspecto cuando comenta otra comedia con protagonista real inglés, El conde de Essex de Coello, indicando que: «Precepto es inviolable de la comedia que ninguno de los personajes tenga acción desairada ni poco correspondiente a lo que significa [...]. Pues ¿cómo se ha de poner una princesa indignamente? Y más cuando la poesía enmienda a la Historia». Bances apostilla también en otros pasajes de su Teatro, que «aunque sea del palacio de la China, sólo por el nombre lleva el poeta gran cuidado en poner decorosa la alusión, venerando por imágenes aun las sombras de lo que se puede llamar real ${ }^{33}$ ». Calderón asigna, entonces, el papel de Alejandro Farnesio de la obra lopiana a Don Lope de Figueroa, convertido en depositario de los valores positivos de la nobleza militar (frente a la soldadesca o a la nobleza poco virtuosa de Don Álvaro de Ataide; de hecho la solución final al conflicto trágico de El alcalde de Zalamea hace necesaria la intervención pacificadora del rey Felipe II).

A partir de esta compleja construcción de los caracteres, Calderón dispone de los mimbres necesarios para llevar a cabo la confrontación de dos personajes a través de un conglomerado de réplicas simétricas de explícita comicidad en algunos casos. De esta manera, Don Lope interviene en cinco secuencias, siempre acompañado de Pedro Crespo: la primera es la secuencia de la habitación de Isabel, cuando Crespo y Juan se enfrentan al Capitán y al Sargento (I, vv. 777-894); la segunda es la de la cena en el jardín, al día siguiente (II, vv. 1077-1396); la tercera, la de la despedida en la que don Lope regala a Isabel la vieira de plata (II, vv. 1501-1575); la cuarta, la de la vuelta a Zalamea, tras la noticia del apresamiento del capitán (III, vv. 2501-2625); la quinta y final, la del pleito ante el rey Felipe II (III, vv. 2626-2767). Baste re-

31 Ver Arellano, 1994, pp. 48-49.

32 Teatro de los teatros, ed. Moir, 1970, p. 35.

33 Teatro de los teatros, ed. Moir, 1970, pp. 34-35. 
cordar los conocidos versos insertos en esa segunda secuencia (vv. 1129-1150):

\author{
Yo, señor, siempre respondo \\ en el tono y en la letra \\ que me hablan; ayer vos \\ así hablabais, y era fuerza \\ que fuera de un mismo tono \\ la pregunta y la respuesta. \\ Demás de que yo he tomado \\ por política discreta \\ jurar con aquel que jura, \\ rezar con aquel que reza. \\ A todo hago compañía; \\ $y$ es aquesto de manera, \\ que en toda la noche pude \\ dormir, en la pierna vuestra \\ pensando, y amanecí \\ con dolor en ambas piernas; \\ que por no errar la que os duele, \\ si es la izquierda o la derecha, \\ me dolieron a mí entrambas. \\ Decidme, por vida vuestra, \\ cuál es, y sépalo yo, \\ porque una sola me duela.
}

Arata $^{34}$ ve en estas simetrías discursivas una muestra de la asimetría (como sugiere en un plano simbólico la cojera de Don Lope) que media entre un Lope de Figueroa «cuya cordura está permanentemente puesta en entredicho por la incontrolada violencia de sus instintos, violencia que acaba enajenándolo de sí mismo de la misma manera que la gota le arranca alaridos de dolor», y un Pedro Crespo «quien presenta la máxima virtud del héroe calderoniano [...]: la capacidad de erradicar los instintos que enajenan al hombre, sometiéndolos al control heroico de la voluntad».Y concluye: «Hay que insistir en que Crespo no es un personaje sin pasiones, como pretenden sus detractores, sino todo lo contrario. Su forma de actuar rebosa apa-

${ }^{34}$ Arata, 2002, pp. 15-16. 
sionamiento, pero por encima de la pasión se sobrepone siempre esa voluntad heroica capaz de encauzar y dominar los instintos».

A mi modo de ver, si se atiende al mensaje global de la tragedia (al fin y al cabo es principio rector de toda la materia dispuesta), lo que resalta precisamente es la asimetría de la simetría. Una simulada simetría que esconde una asimetría inicial relacionada con el honor (drama de honor no conyugal es El alcalde), que un Pedro Crespo, villano, no tiene y que busca fuera de las coordenadas sociales que lo definen. Pero esta suerte de sucedáneo quedará arrumbado cuando el protagonista sufra en sus propias carnes un caso de honra. Hasta aquí llega la comicidad. Sus reliquias apenas son capaces de velar las implicaciones trágicas de las situaciones dramáticas a las que se ven abocados ambos personajes.

En suma, nada más representativo del magisterio calderoniano que esta muestra de comicidad diluida hasta su negación. 


\section{BIBLIOGRAFÍA}

Abrams, F., «Imaginería y aspectos temáticos del Quijote en El alcalde de Zalamea», Duquesne Hispanic Review, 5, 1966, pp. 27-34.

Alemán, M., Guzmán de Alfarache, ed. F. Rico, Barcelona, Planeta, 1987.

Arata, S., "Pedro Crespo y la pata coja de Lope de Figueroa», en Calderón 2000. Homenaje a Kurt Reichenberger en su 80 cumpleaños, ed. I. Arellano, Kassel, Reichenberger, 2002, pp. 3-20.

Arellano, I., «Historia y teatro en el Siglo de Oro. El ejemplo de Calderón», Historia y vida, 74, núm. extra, 1994, pp. 42-49.

- «La risa ausente: el gracioso en las tragedias de Calderón», El escenario cósmico. Estudios sobre la comedia de Calderón, Madrid / Frankfurt, Iberoamericana / Vervuert, 2006a, pp. 33-53.

- "Cervantes en Calderón», en El escenario cósmico. Estudios sobre la Comedia de Calderón, Madrid / Frankfurt, Iberoamericana / Vervuert, 2006b, pp. 123-151, espec. pp. 138-142.

- «Lo trágico y lo cómico mezclado: de mezclas y mixturas en el teatro del Siglo de Oro", en prensa.

Bances Candamo, F. de, Teatro de los teatros, ed. D. W. Moir, London, Tamesis, 1970.

CaAmaño Rojo, M. J., "El mayor monstruo del mundo de Calderón: reescritura y tradición textual», Criticón, 86, 2002, pp. 139-157.

Calderón de la Barca, P., Amar después de la muerte, ed. E. Coenen, Madrid, Cátedra, 2008.

- El alcalde de Zalamea, ed. J. M. Escudero, Madrid / Frankfurt, Iberoamericana / Vervuert, 1998.

Cassol, A., «La figura de Diego García de Paredes en las comedias de Lope de Vega», en "Otro Lope no ha de haber» (Atti del convegno internazionale su Lope de Vega; 10-13 Febbraio 1999), ed. M. G. Profeti, Firenze, Alinea, 2000a, vol. II, pp. 161-180.

- Vita e scrittura. Autobiografie di soldati spagnoli del Siglo de Oro, Milano, Edizioni Universitarie di Lettere Economia Diritto, 2000b.

Castro, M. de, Vida del soldado Miguel de Castro, en Autobiografías de soldados (Siglo XVII), ed. J. M. de Cossío, BAE 90, Madrid, Rivadeneyra, 1956.

Chaves, C. de, Relación de la Cárcel de Sevilla, Madrid, J. Esteban, 1983.

Colección de documentos inéditos para la Historia de España, ed. Marqués de la Fuensanta del Valle, J. S. Rayón y F. de Zabálburu, Madrid, Imprenta de Miguel Ginesta, 1879-1880.

Contreras, A. de, Discurso de mi vida, ed. H. Ettinghausen, Madrid, Espasa Calpe, 1988. 
Diamante, J. B., El defensor del Peñón, en Comedias de Don Juan Bautista Diamante, Madrid, Andrés García de la Iglesia, 1670.

Dixon,V., "El alcalde de Zalamea, la "Nueua": Date and Composition", Bulletin of Hispanic Studies, 77, 2000, pp. 107-115.

Duque de Estrada, D., Comentarios del desengañado de sí mismo, ed. H. Ettinghausen, Madrid, Castalia, 1982.

Escudero Baztán, J. M., "Estudio introductorio», en El alcalde de Zalamea: edición crítica de las dos versiones, Madrid / Frankfurt, Iberoamericana / Vervuert, 1998, pp. 7-89.

Halkhoree, P., "The Four Days of El alcalde de Zalamea», Romanistisches Jahrbuch, 22, 1971, pp. 284-296.

— «Form and Structure», en Calderón de la Barca: "El alcalde de Zalamea», London, Grant and Cutler / Tamesis, 1972, pp. 56-97.

Hendriks, V., «Don Lope de Figueroa, figura histórica e imagen literaria», en Actas del VIII Congreso de la Asociación Internacional de Hispanistas, ed. A. D. Kossoff, J. Amor y Vázquez, R. H. Kossoff, G. W. Ribbans, Madrid, Istmo, 1986, vol. I, pp. 703-708.

Leavitt, S. E., "Cracks in the Structure of Calderón's El alcalde de Zalamea», en Hispanic Studies in Honor of Nicholson B. Adams, ed. J. E. Keller y K. L. Seling, Chapel Hill, University of North Carolina Press, 1966, pp. 93-96.

Menéndez Pelayo, M., "El alcalde de Zalamea", en Obras completas, tomo VIII (Estudios y discursos de crítica histórica y literaria, vol. III), ed. E. Sánchez Reyes, Santander, Aldus, 1941, pp. 353-366.

NaGy, E., "La picardía castrense en Flandes y su utilización en Lope de Vega», en Lope de Vega y los orígenes del teatro español. Actas del I Congreso Internacional sobre Lope de Vega, ed. M. Criado del Val, Madrid, Edi-6, 1981, pp. 765-775.

Oleza, J., «Estudio preliminar», en Lope de Vega, Peribáñez y el comendador de Ocaña, ed. D. McGrady, Barcelona, Crítica, 1997, pp. 3-45.

PArker, A. A., "La estructura dramática de El alcalde de Zalamea», en La imaginación y el arte de Calderón. Ensayos sobre las comedias, Madrid, Cátedra, 1991a, pp. 42-79.

- «El conflicto padre-hijo», en La imaginación y el arte de Calderón. Ensayos sobre las comedias, Madrid, Cátedra, 1991b, pp. 99-118.

Pasamonte, J. de, Vidas y trabajos de Jerónimo de Pasamonte, en Autobiografías de soldados (siglo XVII), ed. J. M. de Cossío, BAE 90, Madrid, Rivadeneyra, 1956.

Poesía erótica del Siglo de Oro, ed. P.Alzieu, R. Jammes e Y. Lissorgues, Barcelona, Crítica, 1984.

Quevedo, F. de, Poesía original completa, ed. J. M. Blecua, Barcelona, Planeta, 1981.

- Prosa festiva completa, ed. C. C. García Valdés, Madrid, Cátedra, 1993. 
Rico, F., Problemas del «Lazarillo», Madrid, Cátedra, 1987.

RuANo, J. M., «Las dos versiones de El mayor monstruo del mundo de Calderón», Criticón, 72, 1998, pp. 35-47.

Rubiera Fernández, J., «Función dramática y funciones dramáticas del gracioso en La hija del aire», en La construcción de un personaje: el gracioso, ed.

L. García Lorenzo, Madrid, Fundamentos, 2005, pp. 225-249.

SABOr de Cortázar, C., «De nuevo sobre la estructura de El alcalde de Zalamea», Estudios (Instituto de Teatro de Barcelona), 2, 1982, pp. 21-37.

Salomon, N., Lo villano en el teatro del Siglo de Oro, Madrid, Castalia, 1985.

SÁnchez, A., "Reminiscencias cervantinas en el teatro de Calderón», Anales cervantinos, 6, 1957, pp. 262-270.

Sloman, A. E., «Scene division in Calderón's El alcalde de Zalamea», Hispanic Review, 19, 1951, pp. 66-71.

SuÁrez, P., Historia del obispado de Guadix y Baeza, Granada, Antonio Román, 1696.

Ter Horst, R., "A new literary history of don Pedro Calderón», en Approaches to the Theater of Calderón, ed. M. D. McGaha, Lanham, Maryland, U. P. of America, 1982, pp. 33-52.

Vega, L. de, El asalto de Mastrique, en Comedias de Lope de Vega, Parte IV (vol. I), ed. E. di Pastena, Lleida, Editorial Milenio, 2002.

- El asalto de Mastrique, en Obras de Lope de Vega, vol. XXVII (Crónicas y leyendas dramáticas de España), ed. M. Menéndez Pelayo, Biblioteca de Autores Españoles, 225, Madrid, Atlas, 1969.

- Tres comedias madrileñas (El mesón de la corte, De cosario a cosario, Santiago el verde), Madrid, Consejería de Educación y Cultura, 1992.

Vélez de Guevara, L., El águila en el agua y batalla de Lepanto, ed. E. Paz y Mélia, Revista de Archivos, Bibliotecas y Museos, 10, 1904, pp. 180-200, 307325; 11, 1904, pp. 50-67.

- El cerco del Peñón de Vélez, en Doce comedias de Lope de Vega y Carpio, Parte XIX, Huesca, Pedro Lusón, 1634.

VITSE, M., Éléments pour une théorie du théâtre espagnol du XVIIe siècle, Toulouse, France-Ibérie Recherche, Université de Toulouse-Le Mirail, 1988.

Wilson, E. M., "Calderón y Cervantes», Hacia Calderón. Quinto coloquio anglogermano, Oxford 1978, ed. H. Flasche y R. D. F. Pring-Mill, Wiesbaden, Franz Steiner, 1982, pp. 9-19.

YNDURÁin, D., "El alcalde de Zalamea, historia, ideología, literatura», Edad de Oro, 5, 1986, pp. 299-311. 